\section{Global Journal of Foreign Language Teaching}

Volume 09, Issue 3, (2019) 167-183

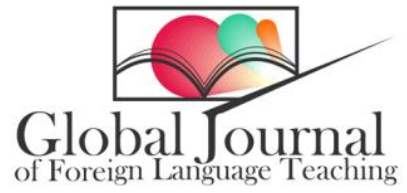

www.gjflt.eu

\title{
Addressing air traffic controllers' English language proficiency needs: Case of Zenata Airport
}

Ghania Mekkaoui*, Department of English, English for Specific Purposes, Faculty of Literature and Foreign Languages, Mustapha Stambouli Mascara, Algeria

Noureddine Mouhadjer, Department of English, English for Specific Purposes, Faculty of Literature and Foreign Languages, Aboubkre Belkaid University Tlemcen, Algeria

\section{Suggested Citation:}

Mekkaoui, G. \& Mouhadjer, N. (2019). Addressing air traffic controllers' English language proficiency needs: Case of Zenata Airport. Global Journal of Foreign Language Teaching. 9(3), 167-183. https://doi.org/10.18844/gjflt.v9i3.4245

Received from January 05, 2019; revised from April 11, 2019; accepted from July 24, 2019.

Selection and peer-review under responsibility of Assoc. Prof. Dr. Jesus Garcia Laborda, Alcala University, Spain.

${ }^{{ }} 2019$ United World Centre of Research Innovation and Publication. All rights reserved.

\begin{abstract}
The current paper is a contribution to the field of English for Specific Purposes (ESP) in aviation industry in an Algerian context. It was conducted in Zenata - Messali el Hadj Airport. It was a case study research that is intended to explore the English language deficiencies and problems Algerian air traffic controllers may face in their work, as well as to identify their lacks, needs and wants. To overcome their difficulties a needs identification and analysis was conducted thanks to various instruments: Interviews, a questionnaire and classroom observation. The results indicated that all informants involved in the current research were aware of the importance of the English language in aviation industry, as low proficiency in this language might lead to misunderstanding and dangerous situations. Air traffic controllers reveal their need to develop their language proficiency, namely in speaking and listening skills with special focus on vocabulary and grammar. To conclude English language is important in aviation industry. A good mastery of this language helps avoid misunderstanding and keep aviation safety. Thus, Algerian air traffic controllers need to enhance their English language ability thanks to appropriate English courses and well-trained ESP teachers.
\end{abstract}

Keywords: Air traffic controllers, English for aviation, English for specific purposes, English language proficiency

*ADDRESS FOR CORRESPONDENCE: Ghania Mekkaoui, Department of English, English for Specific Purposes, Faculty of Literature and Foreign Languages, Mustapha Stambouli Mascara, Algeria

E-mail address: ghania.mekkaoui@univ-mascara.dz 


\section{Introduction}

It is widely known that the English language has become the world language. The growth of business and increased occupational mobility has given this language more territories and spread. Consequently, it became a requirement for professional promotion and even employment; this is the case of aviation industry. A pilot or air traffic controller, with limited English language ability, will be completely excluded from international operations. Nowadays, English proficiency becomes a necessity and even mandatory in aviation industry. Lack of proficiency in this language may not be a primary cause of aviation accidents but may cause aviation incidents. The fact of just Knowing the specialised jargon used in air traffic communication does not seem sufficient. It is true that air traffic controllers and pilots are well trained in specialised phraseology, and in a well-organised communication between them as the structure is clearly defined and the domain is narrowly constrained. However, in non-routine situations misunderstanding and miscommunication may occur.

Two important concerns guide this study: To identify the needs and wants of air traffic controllers and to suggest adequate English course for these informants. The present paper aims at answering the following questions:

1. What English language difficulties do Algerian air traffic controllers face on the job?

2. What are the English language needs, lacks and wants of the Algerian air traffic controllers?

3. What suggestions can be provided to help Algerian air traffic controllers overcome English language difficulties?

To investigate these questions the researcher put forward the following hypotheses:

1. Algerian air traffic controllers face communication difficulties with their English speaking counterparts.

2. Algerian air traffic controllers need to develop their listening and speaking skills with special focus on grammar and vocabulary.

3. Algerian air traffic controllers will better perform in their work place by providing them with adequate English course for aviation teaching.

Language problems have become such a concern that all air traffic controllers and even pilots must meet new standards for English proficiency. The following section will clearly explain why English was chosen to be the language of international communication, how English is classified as subset of English for Specific Purposes (ESP), and why it is necessary to develop a minimum level of English. All these issues will be explained in detail. It is of paramount importance to define first what ESP is?

\section{Literature Review}

\subsection{Definition of ESP}

It is defined differently; some describe it as 'ESP consists of English language teaching which is a goal-oriented language teaching or a type of ELT (English Language Teaching)'. Robinson (1991. p. 2) Makey \& Mountford (1978. p. 4) in their turn believe that.

'The only practical way in which we can understand the notion of special language is as a restricted repertoire of words and expressions selected from the whole language because that restricted repertoire covers every requirement within a well-defined context, task or vocation'.

Many scholars define ESP as an umbrella term that encompasses different branches. Hutchinson and Watters (1987. p. 17) see that ESP can be divided into three branches to suit different teaching situations; English for Science and Technology (EST), English for Business and Economy (EBE) and 
English for Social Sciences (ESS). These branches can be either English for Academic Purposes (EAP) or English for Occupational Purposes (EOP).

The demand for English in both academic and occupational contexts has proved to be more challenging. According to Robinson (1991. p. 3), 'Major distinction of ESP is often drawn between EOP, involving work-related needs and training and EAP, involving academic setting'

The emergence of different subjects and disciplines with different needs leads to the emergence of different programs; some have given other subdivisions of ESP when they classify language learners who need ESP into two categories (Knight, Lomperis, Van Naerseen and Wester Field (2010, p. 7))

1. Learners who are in the process of developing expertise in their fields need English communication skills as tools in their training.

2. Language learners who are already experts in their fields need communication skills as a tool in their process.

In this vein, Lomperis (1998) divided ESP courses into two sub-categories: English in preparation for Employment (EPE) and English for employment purposes (EEP). English for professional purposes (EPP) is divided into three sub-categories: Pre-vocational English (PVE), vocational English (VE) as a second language and EAP. EEP is divided into EOP and EPP.

Dudley and Magie (2002) suggested new classifications; new sub-categories are to be found. For them, EOP is divided into two sub-categories EPP includes English for Medical Purposes and English for Business Purposes and English for Vocational Purposes which is sub-categorised into smaller categories such as PVE and VE this will be clearly explained in the following Diagrams 1 and 2.

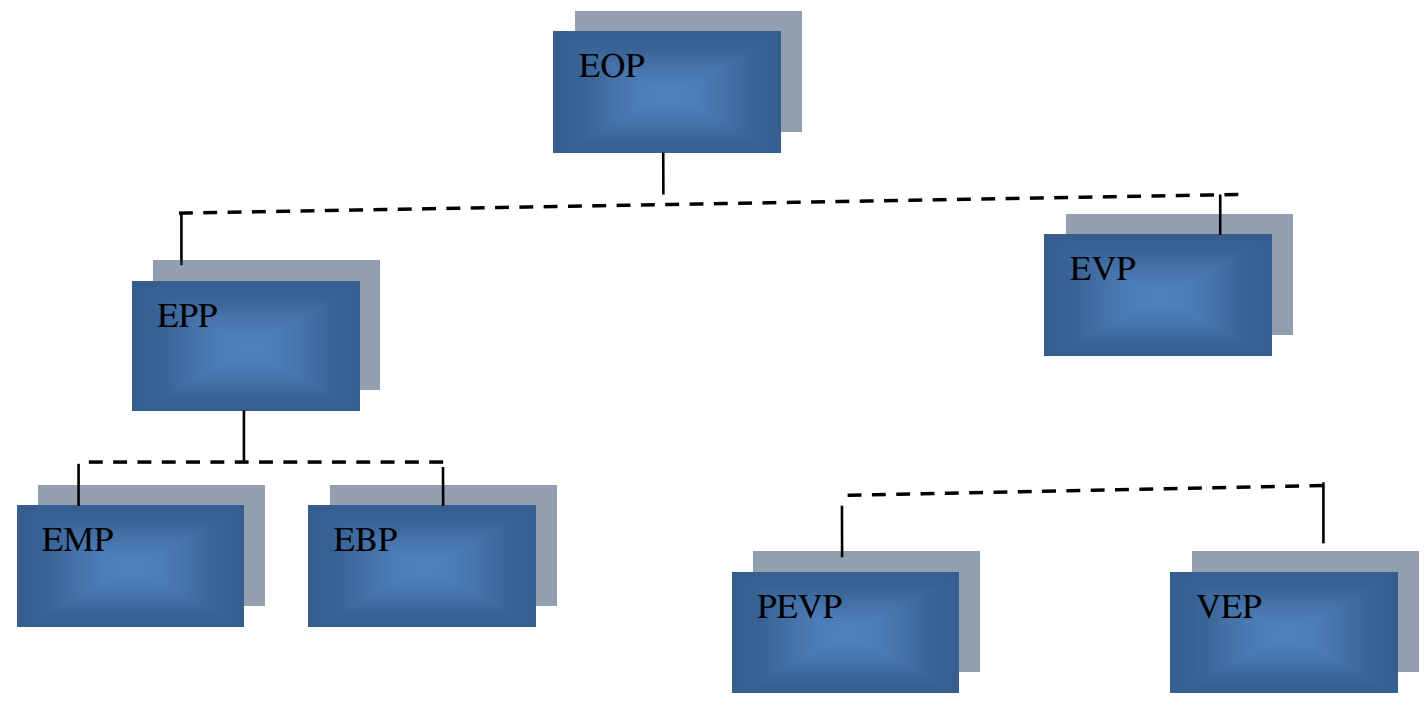

Diagram 1. Dudley Evans and Maggie's sub - divisions of English for Occupational Purposes (2002) 
Mekkaoui, G. \& Mouhadjer, N. (2019). Addressing air traffic controllers' English language proficiency needs: Case of Zenata Airport. Global Journal of Foreign Language Teaching. 9(3), 167-183. https://doi.org/10.18844/giflt.v9i3.4245

\subsection{English for aviation as a sub-division of ESP}

The English used in aviation is not English for General Purposes or English for International Purposes, it is considered as a sub-division of ESP Douglas (2000) in this respect Wang (2008. p. 254) says:

'Accordingly, aviation English can be a sub-division of ESP, in the same rank as EBE, EST and ESS'. 'The core of aviation communication is radiotelephony phraseology, but when this latter does not suffice pilots and air traffic controllers use plain language, this will be clearly explained in the following title.

\subsection{Phraseology and plain language as subset of English for aviation}

It is agreed that phraseology represents only a very narrow, specialised and rigid subset of the English language. That is why the International Civil Aviation Organization (ICAO) has recommended all pilots and air traffic controllers to meet the new English language proficiency requirements. In this vein Stephany (2011) says that phraseology is used to cover the most common and routine situations encountered in air navigation to optimise and ensure safety in communication. Basturkmen Elder (2004) defines phraseology as follows:

Phraseology is meant to cover all routine situations. It is an example of a language for specific purposes, in other words, a language that is used in constrained and predictable ways for a limited range of communicative events.

Carver (1983), in his turn, identifies three types of ESP: English as a restricted language, English for Academic and Occupational Purposes and English with Specific Topics. He considers the language used by pilots and air traffic controllers as restricted one. In this sense, Mountford and Mackey (1978. p. 4) believe that.

The language of international air traffic control could be regarded as 'special', in the sense that the repertoire required by the controller is strictly limited and can be accurately determined situationally, as might be the linguistic needs of a dining-room waiter or air hostess. However, such restricted repertoires are not languages, just as a tourist phase phrasebook is not grammar.

It is essential for reason of safety that aircrew and controllers have to follow agreed procedures to ensure that every part of the message is understood. Air traffic communication involves the use of phraseology, plain language and sometimes adopted regional or local phraseology, which is used in a concise and comprehensible manner as standard phraseology 'Knowing a restricted language would not allow the speaker to communicate effectively in novel situations, or in context outside the vocational environment' Mountford and Mackey (1978. p. 4).

When phraseology is not enough they use plain English to better understand and avoid any misunderstanding or miscommunication in ICAO Manuel (2004. p. 14), plain English was defined.

The spontaneous, creative and non-coded use of a given natural language, although constrained by the functions and topics (aviation and non-aviation) that are required by aeronautical radiotelephony communications as well as by specific safety-critical requirements for intelligibility, directness, appropriacy, non-ambiguity and concision.

According to Morrow, Daniel, Rodvold, Michelle, Lee, Alfred (2004), when the communication becomes problematic, plain English tend to be favoured by speakers and addressees to make sure that what they have understood correctly. It should be noted that plain is used when phraseology could cover the situation, but it never replaces it, plain English cannot replace phraseology. 
Using plain English could provoke another problem, in this sense; Morrow et al. (1994. pp. 253254) says 'because of their tendency to use 'more complex syntax, vague or non-standard terminology 'plain English'; in other words, is not very plain'.

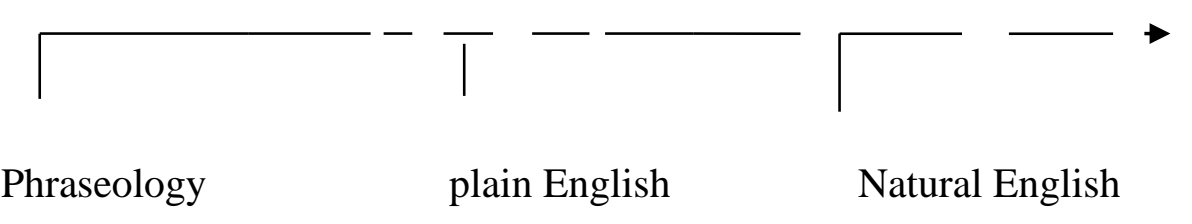

Diagram 2. Relationship between phraseology, plain English and natural English. Adapted from

Stephany (2011. p. 26)

It should be noted that plain language is less restricted than phraseology but not like natural English in everyday speech. In this respect, Stephanie (Ibid) says 'Plain English is less restricted than phraseology but not as natural as everyday speech'. Aviation English is not restricted only to phraseology and plain English that are used by pilots and air traffic controllers; there are other users of English in the aviation industry such as cabin crew, engineer and mechanics, and this will be clearly illustrated in the following Figure 1.1:

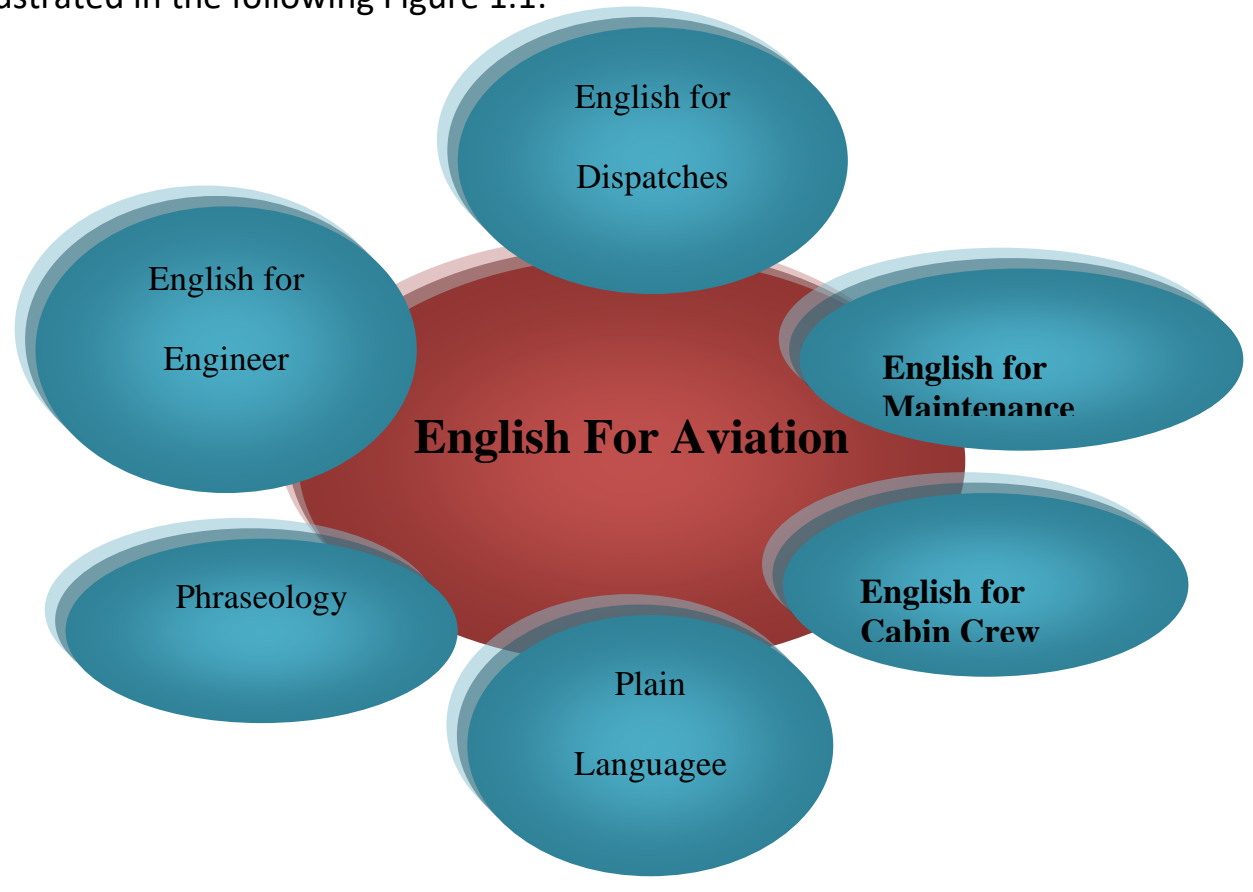

Figure 1.1. English for aviation

\subsection{The need of English in aviation industry}

Almost every field has its own 'Jargon' or its specialised words and phrases used in everyday work fields. However, the jargon in aviation industry can be much more complicated and complex as well as extremely important for clarity and sometimes even safety. Consequently, the demand for ESP has grown considerably in recent years in aviation industry. English becomes a requirement for 
professional promotion and even employment. English language proficiency becomes a necessity in workplace as Philipson (1992. p. 6) points out

English has a dominant position in science, technology, medicine, and computers, in research, books periodicals, and software in transactional business, trade, shipping, and aviation, in diplomacy and international organisations, in mass media entertainment, news agencies and journalism, in youth culture and sport; in education system as the most widely learnt foreign language.

The English language is widely used in the field of aviation in which they use it as a primary medium for communication in international operations. It plays an important role in communication between pilots and air traffic controllers since they had never been in face-to-face communication, they communicate with each other through radiotelephony as Smith(2000. p. 52) claims 'English is often claimed to be the international language for international radio communication'. It should be mentioned that English problems have played a significant role in various aviation disasters. It represents a strong barrier to effective communication, it was claimed that phraseology which is appropriate to provide maximum clarity and brevity in communication it is used only for exchange in routine situations, and however, it is not sufficient in non-routine situations. Uplinger (1997. p. 45) argues:

The mastery of specialised terminology is insufficient to avoid ambiguity. Developing functionality in a foreign language is a difficult task, she says. Moreover, a pilot or ATC who knows 200-300 English air traffic control terms may have little functional ability. In the same vein, Wang (2008. p. 256) also maintains:

Safety experts and linguists are also inclined to agree that phraseologies alone, no matter how extensive, are not sufficient to adequately cover all of the potential situations that can arise from human communication, particularly in aviation for urgent or emergency situations.

\subsection{The ICAO}

New fundamental English language proficiency requirements for pilots and air traffic controllers all over the world were initiated by the ICAO. The latter seeks to promote aviation safety. One of the overarching objectives of ICAO as mentioned in article 43 of the convention they agreed on is to foster the planning and development of international transport to meet the needs of the people for safe, regular, efficient and economical air transport. In this sense, Ragan (2007. p. 54) defines ESP as follows:

The ICAO is a branch of the United Nations that regulate aviation internationally, it establishes and reviews international standards for the licensing of personal and aircraft operations, and develop principles and techniques of air navigation including meteorology, radio communication and rules of the air.

These new regulations came as a solution to miscommunication problems which are the results of insufficient English language for pilots and air traffic controllers who are considered as key players in this scenario. As Nancy Agraham (Director of ICAO Air Navigation Bureau) States:

Due to fatal accidents because of the lack of proficiency in English was identified as a contributing factor. ICAO adopted standards to strengthen language proficiency for pilots and air traffic controllers in international operations.

English was chosen as the lingua franca for international aviation; thus, ICAO recommends that both pilots and air traffic controllers should demonstrate a minimum level that is Level 4 . The ICAO representatives saw that success depends on the standardisation of aviation procedures throughout the world. One area to be standardised was communication. ICAO recommends that English is to be 
available at all control facilities serving international flights. The language suggested by ICAO would be a simplified form of English that would be easy for non-native speakers to master. The ICAO believes in improving communication between pilots and air traffic controllers help reducing accidents where a lack of proficiency can contribute to some extent to such issue. Day (2002. p. 24) notes that 'in the arena of international aviation, English sheds all connections to political agendas, real or perceived and becomes simply another tool for increased safety and efficiency of aviation operations'

ICAO had listed a set of holistic descriptors which outline the plain English requirements as follows:

Proficient speakers shall:

1.

Communicate effectively in voice-only (telephone/radiotelephone) and in face-to-face situations;

2. Communicate in common, concrete and work-related topics with accuracy and clarity;

3. Use appropriate communicative strategies to exchange messages and to recognise and resolve misunderstanding, for example, to check, confirm, or clarify information) in general or work-related context;

4. Handle successfully and with relative ease the linguistic challenges presented by a complication or unexpected turn of events that occur within a context of a routine work situation or communicative task with which they are otherwise familiar and

5. Use a dialect or accent, which is intelligible to the aeronautical community.

\section{The Study}

\subsection{Methodology}

As already mentioned two important concerns guide the current study: (1) To identify the English language needs and wants of air traffic controllers and (2) to see to what extent the lack of the English language ability might affect their work. The present work was carried out at the Algerian airport Zenata currently called Messali el Hadj airport. To describe the situation where the study took place, it is worth pausing to develop a general insight into the airport and the different companies it encompasses.

\subsection{Zenata airport/Messali el Hadj Airport}

It is an Algerian international civil airport situated in the town of Zenata $22 \mathrm{~km}$ Northwest of Tlemcen. The aerodrome was closed in 2007 for renovation with the aim of doubling the number of flights that it could handle. The airport was re-opened in 2008; presently, the airport plays an important role in the region. In 2011, Tlemcen was the capital of Islamic culture; consequently, it welcomed and is still receiving many visitors from different countries around the world. This means that the airport itself is a major economic force for the country both in terms of its operations and its impact on related industries including tourism, because of the number of foreign visitors visiting our country through this airport, people working in this airport and the supporting industries need to know foreign languages especially the English language.

The airport provides service to national and international destinations such as Algiers, Paris, Orly and Marseille under the direction of two companies. A local one is known as Air Algerie (Algerian Airlines) and an international one known as Aigle Azur. A third company which is a local one offers one 
flight each Saturday to Hassi Rmel known as Tassili Airlines. All these companies work in collaboration with the national air navigation company known as 'ENNA' (Enterprise National de la Navigation Aerianne)'. The primary concern of each company is to ensure safety of flights and comfort to passengers.

\subsection{Research design}

To have a thorough examination of a particular situation or phenomenon, the case study is appropriate. It is well suited because of its ability to answer the research questions mentioned earlier as Punch (1998. p. 150) states 'case study method allows for a variety of research questions and purposes which allows the researcher to develop a full understanding of that case as possible'. A case study is considered by Benbasat (1987. p. 370) to be reliable for three reasons

1. It is necessary to study the phenomenon in its natural setting

2. The researcher can ask how and why questions, so as to understand

3. The nature and complexity of the process taking place.

Research is the preliminary study of unfamiliar problem about which the research has little or complexity of the process taking place. Moreover, Yin (1993. p. 4) distinguishes three types of case studies 'exploratory, explanatory and descriptive'. Isaac \& Michael point out (1998. p. 52) that 'case study is exploratory in nature, and the outcome of a case study may provide information and possible hypothesis to guide research'. To understand and explore what English language difficulties do Algerian air traffic controllers encounter when using the English language difficulties do Algerian air traffic controllers encounter when using the English language during their work and what are their needs, lacks and wants. The researcher opted for a case study research, according to Patton (1987. p. 19)

One needs to understand some particular problem or situation in great depth, and where one can identify cases rich in information-rich in the sense that a great deal can be learned from a few examples of the phenomenon in question. For example, a great deal can often be learned about how to improve a program by studying selected dropouts; failures or success.

It is worthy to mention that the current case study is the first exploratory research to tackle the field of English for Aviation in Algeria. Indeed it is a pioneering work in current ESP research in Tlemcen, according to Khan (2009. p. 12)

Exploratory no knowledge; it is similar to doctor's initial investigation of the patient suffering from an unfamiliar malady for getting some clues for understanding it.

\subsection{Research instruments}

An essential step in any research is to select appropriate tools that best serve the goals and objectives of the research in hand and more importantly answer the research problematic. In the same way of thinking O'leary (2005. p. 150) says 
Collecting credible data are a tough task, and it is worth remembering that one method of data collection is not inherently better than another, therefore, which data collection to use would depend upon goals and the advantages of each method.

To cross-check findings triangulation was achieved through the implementation of different methods. The researcher used an interview, a questionnaire and classroom observation. Meriam (1998:32) states that 'triangulation is a measure of validity through the use of multiple data collection methods, multiple sources, multiple investigation and/or theoretical perspectives'.

\subsubsection{Interviews}

The current study involves six air traffic controllers, the general director of the National Air Navigation Company and two English teachers.

\subsubsection{Air traffic controllers interview}

The purpose of the interviews used in the current study was not to produce a final inventory of target needs, but merely to obtain a better idea based on insider knowledge as Turckman (1972. p. 45) suggests 'By providing access to what is inside the person' head, it makes it possible to measure what person likes or dislikes (values and performances) and what a person thinks (attitudes and belief)'. The researcher sees that a reliable method to elicit informants' views, and to know about their attitudes would be through interview, this gives the researcher a chance to be in direct contact with her informants and to enter their world which is impossible to be observed directly as Patton (2002. p. 341) says 'we interview people to find out from them those things we cannot directly observe, we have to ask people questions about those things' he adds

Interviews have a higher response rate than questionnaire because respondents become more involved and hence motivated, they enable more to be said about the research than is usually mentioned in a covering letter to questionnaire and they are better than questionnaire for handling more difficult and open-ended questions

Moreover, there are different types of interviews which differ in terms of formality. Three types of interviews can be distinguished: structured, semi-structured and unstructured interviews. In this vein Nunan (1992. p. 149) sees that 'Interviews can be characterised in terms of their degree of formality, and most can be placed on a continuum ranging from structured through semi-structured to structured'. The researcher opted for a structured interview to identify their needs, lacks and wants; it also seeks to explore what difficulties they face when using this foreign language, needs identification interview was conducted, Basturkmen (1989. p. 2) states that

Needs analysis have been identified as the identification of difficulties and standard situation through the adoption of two ways: Observing students functioning in target situations, conducting interview and delivering questionnaire to different group of respondents to find out these difficulties.

The researcher selected the interview as a tool to elicit air traffic controllers' opinions, suggestions and attitudes because: 
1. The group addressed has no time to complete written questionnaire.

2. It gives informants an opportunity to check what is meant by a question allowing for long and clearer responses.

3. It provides clear picture of what participants possess and what he needs to accomplish

4. To have new insights and information from participants, according to Patton (2002:340-41quoted in Merriam 2009) 'We interview people to find out from those things we cannot directly observe'

Regarding the timing of the interview, it was done in $30 \mathrm{mn}-40 \mathrm{mn}$. It consists of close and open questions; close questions are those which allow the respondent to select a number of possibilities offered to him or answered by 'yes' or 'no'. Open questions are those which require a personal answer. The interview covers 16 items and is divided into 16 items and is divided into five sections.

\section{Section One: The Participants' Profile}

This part seeks general information about the respondents; it is made of five items which include their age, level of education and the country where their initial training was completed. This part is essential to gather information about participants at the same time it helps in the analysis of a number of response patterns.

\section{Section Two: The Importance of the English Language}

It includes nine items which cover general information about the importance of the English language in the workplace, the frequency of using that language, the language used during international flights, the most important skills needed to perform successfully and finally any experienced accidents or incident that occurred in their work because of bad command of English language.

\section{Section Three: English Training Program}

It covers three items which seek general information about any English training program and further suggestions for any future training.

\section{Section Four: Suggestion to Overcome Difficulties}

It asks further suggestions to help them overcome difficulties when using this language.

\section{Section Five: Participants' Opinion about the New ICAO Regulations}


This part seeks the respondent's views about the new ICAO English language proficiency requirements.

\subsubsection{The general director interview}

To have a general idea about the context where the research took place it is essential to collect the opinions of different people, especially those who are directly concerned with the management of the area where research took place. In this respect, another interview was conducted with the general director of the National Air Navigation Company, H.long (2005. p. 36) states 'Multiple sources should always be employed, both they add breadth and depth to analysis, and because triangulation of sources offers important means of validating findings'. The interview was divided into four sections; its medium was French, it lasted $20 \mathrm{mn}$.

\section{Section One: Number of Air Traffic Controllers and Number of Flights}

This section seeks to know the number of air traffic controllers working in Zenata airport, the number of flights: Domestic and international ones.

Section Two: The importance of the English language in the work of Air Traffic Controllers

It seeks to know if the English language receives any adequate importance in the airport or not i.e., whether an English training program exists. If not is there any future planning for any training.

\section{Section Three: New Regulations about the English certificates for Air Traffic Controllers}

It seeks to inquire about the existence of any regulation that deprives air traffic controllers of being engaged in international operations.

\section{Section Four: Suggestions}

It seeks to provide further suggestions to prevent English problems that may be one of the causes of an aviation disaster.

\subsubsection{Teacher's interview}

During the researcher presence in the airport, the company has already initiated a workplace English training program for air traffic controllers, this led to the introduction of another research instruments to provide worthwhile and comprehensive data, these instruments were a structured interview to the English teachers enrolled to teach those informants, an unstructured classroom observation and a post-observation questionnaire. Before describing the teacher's interview, it is important to introduce the teacher's profile engaged in the rolling of the English training program.

\section{Teachers' profile}

The teachers involved in the present research are full-time teachers at Mascara University/Algeria (Mustapha Stambouli), who hold Magister degree; both of them have been teaching English for more than 10 years. Those teachers work in collaboration to teach air traffic controllers. One of them (teacher A) teach them, at the end of each level (teacher B) evaluates them, according to him he was 
helping teacher A to apply what has been taught in each level. His job was for evaluative feedback. They call this task coaching session.

It should be noted that teacher A has an ESP teaching experience in different contexts, both in academic and occupational contexts. In 2011, he was a part-time teacher of Business English at Sidi Bel Abess University; he also taught Translation in Tlemcen University, English for Law and English for agronomy. Whereas the second teacher has no experience in teaching ESP, his only experience in teaching ESP was teaching English for controllers. No one teacher has ESP training; according to them such training is not available in our country since ESP in Algeria is still in its first steps.

Regarding the design of the interview, it was a structured one; its main objective is to have the teachers' point of view about the adequate syllabus for air traffic controllers, as well as to see to what extent the English training program matches the needs of air traffic controllers. The interview was divided into five sections.

\section{Section One: Teachers' qualifications}

Bird-eye view about their educational background.

\section{Section Two: Overview of the Course Content and Conduct in the Three First Levels of Instructions}

This section seeks to have further information about the elements included in the program, and the way the content was delivered. It checks whether teachers focused on content that matches the needs of informants or not.

\section{Section Four: Evaluation of controllers' level after the Training Program}

This section asks about the teachers' evaluation of the controllers' level at the end of the training program; in other words, it seeks to see whether controllers had progressed or not.

\section{Section Five: Material Evaluation}

It is about teacher's satisfaction or dissatisfaction of the material used to teach in the training program.

\section{Section: Suggestion}

It provides the researcher with further suggestions to help elaborate a suitable syllabus that helps those informants to satisfy their needs, wants and lucks.

\subsubsection{Air traffic controllers' questionnaire}

Mark Saunders, Philip Lewis and Adrian Thornhill (2009. p. 23) argue that 'a reasonable and moderate-high response rate $(30 \%-50 \%)$ is guaranteed with self-administered questionnaire, hard deliver and collected questionnaire". To ensure the total rate return and to help respondents with clarification when needed, a self-administred questionnaire was delivered just after the end of the 
English training program. It should be noted that the program was made of four levels of instruction, by accident the researcher had chance to attend the last level. The questionnaire was developed for the sake of having satisfactory answers to the following questions:

1. Was the teaching material effective for improving controllers' English competencies?

2. Does the teacher use any teaching aids that help students to improve their English proficiency?

3. Was the time allotted to English teaching sufficient to practice the needed skills?

The major goal of the questionnaire was to see how participants evaluate the training program i.e., whether it was successful and how closely the material match their needs? The idea of using the questionnaire as a tool has a set of advantages, according to Richards (2001. p. 60)

Questionnaires are one of the most common instruments used, they are relatively easy to prepare, they can be used to with large number of subjects, and they obtain information that is relatively easy to tabulate and analyse. They can also be used to elicit information about many different kinds of issues, such language use, communication difficulties, preferred classroom activities and attitudes and beliefs.

In general, speaking, there are three types of questions: Open questions, closed questions and graded questions.

\subsubsection{Classroom Observation}

In response to ICAO new English language proficiency requirement, the National air Navigation Company initiated an English training program for air traffic controllers. More to the point the program was made of four levels of instruction by two teachers as already mentioned. The researcher attended the final level; the course was divided into morning and evening sessions. The researcher attended this level from the beginning till the day of their final examination there were 13 sessions. The researcher opted for an unstructured classroom observation, according to Loftand (1971. p. 32) classroom observation is 'the most penetrating of strategies, the most close and telling mode of gathering information' this was a motive for the researcher to use observation to better explore the situation. Patton (1990. p. 202 quoted in Cohen \& Manion 2007) suggests that observational data should 'enable the researcher to enter and understand the situation that is being described'

Classroom observation may vary from structured to unstructured one as explained by Dyer (1995 quoted in Kevin, 2008. p. 04) 'the difference between structured and unstructured observation is as follows 'structured observation can test hypotheses about specific behaviour while unstructured observation tends to describe all the behaviour in situation». To have a clear idea about the course content and conduct the researcher decided to proceed to an unstructured observation, in this sense Punch (1998. p. 186 quoted in Bell 1991) says: 
Researcher who decided to adopt an unstructured approach of observation; generally do so because though they may have a clear idea of the purpose of the observation, they may not be so clear about the detail, they are prepared to spent sufficient time on the fieldwork, familiarisation and accumulation of data from which they anticipate that focus and structure will emerge

The decision to implement both the questionnaire and classroom observation was to see closely what was practiced closely in all levels, an overall objective is to investigate whether the program enjoyed sufficient and acceptable efficiency in terms of students 'needs, lacks and wants. In this respect, Richards (2005. p. 61) reports that

Observation of learner's behaviour in a target situation is another way of assessing their needs, for example, observing clerks performing their job in a bank will enable an observer to arrive at certain conclusions about their language needs.

\section{Results}

The study was grounded in three Research Questions:

1) What English language difficulties do Algerian pilots and air traffic controllers face

on the job?

2) What are the English language needs, lacks and wants of the Algerian pilots and air traffic controllers?

3) What suggestions can be provided to help Algerian pilots and air traffic controllers

Overcome English language difficulties?

The investigation began with the hope of finding answers to these questions, to do so; the researcher put forward the following hypotheses:

1) Algerian air traffic controllers face communication difficulties with their English speaking counterparts.

2) Algerian air traffic controllers need to develop their listening and speaking skills with special focus on vocabulary and grammar

3) Algerian air traffic controllers will better perform in their workplace by providing them with adequate English course for aviation.

To test these hypotheses i.e., to confirm or disconfirm them and from different sources: Air traffic controllers, the General Director of the National Air Navigation Company, and the English teachers. The first hypothesis was confirmed i.e.; Algerian air traffic controllers face communication difficulties with their English speaking counterparts. The results revealed that their limited knowledge of both general and specific vocabulary prevents them from interacting successfully in any communication; also mention that they are able to understand only a limited number of words and simple expressions 
at slower normal speed and without basic competence of grammar. Speech is always incomplete, full of Grammar mistakes, and their pronunciation is frequently incorrect. All these were noticed in the proficiency test and during the classroom observation. Most of them relate their difficulties to lack of exposure to this language. Besides, it appears that air traffic controllers were aware of what skills they needed to improve. They all revealed that both listening and speaking skills need improvement since their communication is voice only.

The findings of the test also related their difficulties to the negative transfer resulting from their linguistic background (influence of French). They cannot use correct and appropriate English. They can express their taught neither adequately nor correctly. Communicating with their foreign counterparts in the performance of their job may lead to safety risk. Indeed, controllers revealed their current low proficiency and said that they were still far from what they really wished to accomplish. They also unveiled limited knowledge of both general and specific vocabulary prevents them from interacting successfully in any communication. They all asserted their need to master the English language as it is the world language and the currency of exchange, especially in international operations; moreover, all their manuals are in English. They concluded that lack of adequate mastery of English may cause safety problems.

Regarding the second hypothesis that is related to the English language needs, lacks and wants; results confirmed this hypothesis, that is to say, Algerian air traffic controllers need to develop their listening and speaking skills with special focus on grammar and vocabulary.

The results revealed that both speaking and listening skills are important in their daily

work, since communication is voice only, air traffic controllers had severe problems in these skills, concerning the listening skill, the results revealed that most of the time both of them had the same deficiencies, they could neither grasp the gist of conversations, nor express their thoughts freely, because of their lack of appropriate vocabulary, and their unfamiliarity with the different accents of their interlocutors. All these were noticed while testing their English proficiency level. Most of the time their speech is incomplete; their descriptions were meaningless, full of grammar mistakes and incorrect pronunciation.

Regarding the third hypothesis, that is; Algerian air traffic controllers will better perform in their workplace by providing them with adequate English for aviation teaching. It is related to the suggestions that can be given to help them to overcome these difficulties. Informants involved in this study saw that an ESP teaching program is advised for air traffic controllers. They all expressed their wish to be provided with language laboratories to help them develop their language skills, namely listening and speaking, which are required most of the time.

They expressed their wish to have more qualified ESP teachers; they also suggested listening as much as possible to native speakers and experts in aviation industry. They also suggested that controllers should be taught by native speakers and be in contact with controllers from different countries virtually, or be sent to foreign countries to improve their English language command and to communicate effectively. Besides, they require continuous training. 


\section{Conclusions}

English as a world language is gaining more ground in many fields. Air transportation is a case in point. It gives great importance to this language since it is the medium of communication in the aviation industry. All pilots and air traffic controllers, be them natives or non-natives should operate in international flights using English, in other words, being communicatively competent while using the English language is as important for these people as technical proficiency to ensure aviation safety. The present paper was a case study of English language needs of Algerian air traffic controllers in Zenata Airport. It aims at identifying the English language problems that air traffic controllers may face in their work, by shedding light on their lacks, needs and wants, in other words; what these participants need to know to function effectively in their workplace and what English language skills are needed to do their job successfully.

Teaching English for aviation is of vital importance because of the increased realisation that poor command of English causes serious problems for air traffic controllers, such as communication breakdown and misunderstanding. In an attempt to put forward a number of proposals that leads to practice and progress the researcher. In the suggested syllabus, the researcher attempted to help air traffic to have further practice and maximum exposure to day-day language skills necessary for not merely to meet a new standard, but to ensure safe flying everywhere, through this syllabus the researcher tries to offer definitions of technical information related to flying to develop informants' language acquisition skills. Most focus in each unit will help them learn new vocabulary and communicate easily and freely in any situation. The syllabus covers a wide range of topics related to non-routine situations, in such a way informants will be exposed to a variety of situation that they may encounter in their work. An overall aim of the suggested syllabus is to develop air traffic controller's language abilities; it aims at helping them acquire appropriate vocabulary, correct grammar and pronunciation. Each unit has language exercises that develop pronunciation, oral fluency, vocabulary and grammar.

By exploring the problems faced by pilots and air traffic controllers, it may be possible to suggest adequate programs that may help the Algerian air traffic controllers not only to master the phraseology of English for aviation but also more than that to understand and to respond in English even in difficult, unexpected and stressing situations. Furthermore, instead of spending large sums of money on English for aviation training in foreign countries, which is most of the time so costly, its high time to save money for other purposes and to ensure English for aviation in our country. Such an initiative will open doors for both ESP teachers and ESP students and it is a worthy investment for the country. This investment in aviation will reduce costs and save money for other purposes.

\section{References}

Basturkmen, H. (2006). Ideas and option in English for specific purposes. London: Lawrence Erlbaum Associated Publishers.

Bell, J. (1993). Doing your research project: A guide for time researchers in education and social science. (2 ${ }^{\text {nd }}$ ed). Buckingham: Open University Press.

Benbasat, I., Goldstein, D. K., \& Mead, M. (1987). The case research strategy in studies of information systems. MIS Quarterly, 11, 369-386.

Cardosi, K., Falzarano, P., \& Han, S. (1998). Pilot-controller communication errors: An analysis of aviation safety reporting system (ASRS) reports. Cambridge, MA: Federal Aviation Administration.

Carver, D. (1983). Some propositions about ESP. The ESP Journal, 2, 131-137.

Cohen, L., \& Manion, L. (2007). Research methods in education. (5 $5^{\text {th }}$ ed). London: Routledge Falmer.

Cushing, S. (1994). Fatal words: Communication clashes and aircraft crashes. Chicago: University of Chicago Press.

Cushing, S. (1995). Pilot-air traffic control communications: It's not (only) what you say, it's how you say it. Flight Safety Digest, 14(7), 1-10. 
Day, B. (2002). Proposed ICAO proficiency requirements in common English. Paper Presented at the $8^{\text {th }}$ International Aviation English Association Seminar, Warsaw, Poland.

Day, B. (2002). Safe radiotelephony demands good discipline from all pilots and controllers. ICAO Journal, 57, 24-25.

Douglas, D. (2000). Assessing languages for specific purposes. Cambridge, England: Cambridge University Press.

Dudley, E., \& Magie, J. (1998). Development in ESP: A multi-disciplanary appraoch. Cambridge: Cambridge University Press.

Dudley, E., \& Magie, J. (2002). Development in ESP: A multi-disciplanary approach. Cambridge: Cambridge University Press. 